\title{
Detección de Neospora caninum por PCR anidada en leucocitos de bovinos productores de leche
}

\section{Detection of Neospora Caninum by PCR nested in leukocytes from dairy bovines}

\author{
Raúl Miguel Reyes-Sandoval ${ }^{1}$,Jesús Antonio Álvarez-Martínez ${ }^{2}$, Carmen Rojas-Martínez ${ }^{2}$, Enrique \\ Espinosa-Ayala ${ }^{1}$, Virginia Guadalupe García-Rubio ${ }^{1}$, Juan José Ojeda-Carrasco ${ }^{1 *}$ \\ ${ }^{1}$ Universidad Autónoma del Estado de México. Centro Universitario Amecameca. Carretera Amecameca-Ayapango Km 2.5, \\ CP. 56900. Amecameca, Estado de México, México. \\ ${ }^{2}$ Centro Nacional de Investigación Disciplinaria en Parasitología Veterinaria, INIFAP. Carretera Federal Cuernavaca-Cuautla No. \\ 8354 Col. Progreso, CP. 62550. Jiutepec, Morelos. México. \\ *Autor de correspondencia: jjojedac@uaemex.mx; mvzojeda @hotmail.com
}

Nota científica recibida: 23 de noviembre de 2016 aceptada: 22 de febrero de 2017

RESUMEN. Se evaluó la seropositividad a Neospora caninum mediante ensayo inmunoenzimático (ELISA) y se detectó el ADN por PCR anidada con iniciadores externos Np 21-4 e internos Np 9-10 en leucocitos de vacas del sistema de producción de leche en pequeña escala en Amecameca, Estado de México. Se estudió un hato con 34 hembras adultas realizando el seguimiento con muestreos sanguíneos durante cinco meses; también, se analizaron dos muestras de encéfalo de fetos abortados y se constató la secuencia de los amplicones en el Genbank. La concordancia entre técnicas fue comparada mediante la prueba Kappa. La seroprevalencia por ELISA fue de $85.3 \%$; y se detectó ADN del parásito en $89.4 \%$ de las vacas. Una muestra de encéfalo fue positiva. La similitud de los amplicones osciló entre 91 y $96 \%$, el índice Kappa fue de 0.41. El empleo de leucocitos aumenta la probabilidad de amplificar ADN de $N$. caninum.

Palabras clave: Detección, leucocitos, Neospora caninum, PCR

ABSTRACT. Seropositivity to Neospora caninum was evaluated by Enzyme-Linked ImmunoSorbent Assay (ELISA) and the DNA was detected by PCR nested with external initiators Np 21-4 and internal Np 9-10 in cow leukocytes from the small-scale milk production system in Amecameca, State of México. A herd with 34 adult females was studied, performing follow-up with blood sampling for five months. Also, two brain samples from aborted fetuses were analyzed and the sequence of the amplicons in the Genbank was verified. Consistency between techniques was compared using the Kappa test. ELISA seroprevalence was $85.3 \%$; and DNA of the parasite was detected in $89.4 \%$ of the cows. A brain sample was positive. The similarity of the amplicons ranged from 91 to $96 \%$, the Kappa index was 0.41 . The use of leukocytes increases the likelihood of amplifying N. caninum DNA.

Key words: Detection, leukocytes, Neospora caninum, PCR

\section{INTRODUCCIÓN}

El sistema de producción de leche en pequeña escala (SPLPE) se caracteriza por contar con hatos entre tres y 35 vacas en producción, depender de la mano de obra familiar y el escaso o nulo uso de tecnologías, además de tener pequeñas superficies de tierra que se cultivan para proveer alimento al hato (López et al. 2008). Tienen gran capacidad de adaptación a los cambios, por lo que se ha convertido en una buena opción para el desarrollo rural (Espinosa-Ortega et al. 2007). En México el $28 \%$ de la producción láctea la aporta el SPLPE (Hernández et al. 2013); pero se encuentra amenazado por factores que aminoran su funcionalidad como el manejo inadecuado, la malnutrición y las enfermedades metabólicas e infecciosas (Ojeda et al., 2016). Actualmente, se considera a la neosporosis 
bovina la principal causa de aborto a nivel mundial; la cual es ocasionada por el parásito protozoario Neospora caninum del Phylum Apicomplexa (Wilson et al. 2016); la enfermedad se caracteriza por ocasionar aborto entre el tercero y noveno mes de gestación, aunque es más común entre el cuarto y sexto. Además, puede causar reabsorción embrionaria, muerte fetal temprana, mortinatos y muerte neonatal, provocando un efecto negativo en los diferentes parámetros reproductivos y en la producción de leche, lo que predispone al desecho prematuro de vacas (Adekunle e Ibikunle 2013).

El perro (Canis familiaris), el coyote (Canis latrans) y otros cánidos silvestres, actúan como hospederos definitivos, teniendo un papel importante en la transmisión horizontal de la enfermedad (Dubey et al. 2014); respecto a los hospederos intermediarios, han sido reportadas diversas especies, como los bovinos, caprinos, ovinos (Dubey et al. 2007) y aves domésticas (Costa et al. 2008). La detección de anticuerpos específicos contra $N$. caninum es un buen indicador de la exposición de los animales al parásito, la inmunofluorescencia indirecta (IFI), la prueba de aglutinación, el ensayo inmunoenzimático (ELISA) y el inmunoblot han sido empleados con este fin (Almería 2013). La identificación de anticuerpos, no necesariamente indica la presencia del parásito al momento de la toma de muestras, ninguna de éstas pruebas puede detectar la infección en fetos y la especificidad y sensibilidad diagnóstica de las mismas puede variar (Yao et al. 2009). En contraparte, la prueba de diagnóstico directo de reacción en cadena de la polimerasa (PCR) con sensibilidad y especificidad elevada, tiene la capacidad de amplificar el ADN de $N$. caninum en tejidos de fetos abortados y de animales adultos, fluidos corporales como líquido amniótico, cefalorraquídeo, sangre, leche y semen (Yao et al. 2009, González-Warleta et al. 2014). Aun, cuando este tipo de prueba ofrece grandes posibilidades para el diagnóstico, el procedimiento enfrenta limitantes asociadas a la dificultad para obtener los fetos abortados en buen estado o tejidos que solo pueden ser obtenidos posmortem (Yao et al. 2009). Además, la baja concentración de parásitos en dichos tejidos, o en fluidos como semen y leche, hacen que la búsqueda de ADN de $N$. caninum en sangre sea una buena opción para el diagnóstico de la neosporosis antemortem (Okeoma et al. 2004). El gen repetitivo específico Nc-5 y el espaciador de transcripción interno (ITS1) son los marcadores más utilizados para la detección de $N$. caninum con PCR (Donahoe et al. 2015). Se ha reportado la detección de ADN del parásito en la fracción de células blancas de la sangre de vacas seropositivas (Okeoma et al. 2004, Marques et al. 2011), así como en suero de animales seronegativos y seropositivos (Mc Innes et al. 2006). Por lo anterior, el objetivo del presente estudio fue estimar la seroprevalencia mediante ELISA y detectar ADN de $N$. caninum por medio de PCR anidada en leucocitos de vacas del SPLPE.

\section{MATERIALES Y MÉTODOS}

\section{Área de estudio}

La investigación se realizó en el municipio de Amecameca, ubicado a una altura de 2400 msnm, tiene clima templado subhúmedo $\mathrm{Cb}$ (w2) con precipitación pluvial promedio de $935 \mathrm{~mm}$, localizado en el sur-oriente del Estado de México (INAFED 1998).

\section{Población bajo estudio}

Se trabajó en un hato característico del SPLPE, con 34 hembras de fenotipo Holstein en etapa reproductiva, identificado previamente como seropositivo a $N$. caninum (Ojeda-Carrasco et al. 2016). El seguimiento se realizó de marzo a julio de 2015. Las vacas presentaban entre uno y siete partos; con nueve vacas del primer trimestre de gestación, nueve del segundo, cinco del tercero y 11 sin preñez.

\section{Manejo del hato}

La dieta se basó en ensilado de maíz, forraje de alfalfa, heno de avena y se suplementó con alimento balanceado comercial con $18 \%$ de proteína cruda; se pastoreo en praderas artificiales de alfalfa, en la época de estiaje. El manejo reproduc- 
tivo se realizó sin modificar el protocolo habitual de la unidad de producción mediante el uso de inseminación artificial. Se implementó un programa de vacunación desde 2012, inmunizando contra Brucelosis, Diarrea Viral Bovina, Rinotraqueítis Infecciosa Bovina, Parainfluenza tipo 3, Virus Sincitial Respiratorio Bovino y Leptospirosis con cinco serovariedades, agentes etiológicos relacionados con la producción de aborto en el bovino.

\section{Muestreo}

La toma de muestras sanguíneas se efectuó cada mes durante cinco ocasiones, la cual se realizó por punción de la vena coccígea, utilizando tubos tipo vacutainer, sin anticoagulante para la prueba de ELISA en el muestreo inicial y con EDTA para la $P C R$. Las muestras sin anticoagulante se centrifugaron a $1000 \times$ g durante $15 \mathrm{~min}$, conservando el suero en tubos de poliestireno a $-20{ }^{\circ} \mathrm{C}$ hasta su utilización.

\section{ELISA}

La detección de anticuerpos específicos contra $N$. caninum se llevó a cabo al inicio del estudio por ensayo de inmunoenzimático (ELISA), empleando un paquete comercial (HerdCheck antiN. caninum, IDEXX ${ }^{\mathrm{TM}}$-Laboratories Inc.) con 100 $\%$ de sensibilidad y $98.9 \%$ de especificidad, usando una dilución de los sueros de 1:100, cada muestra se analizó por duplicado y la lectura de las placas se verificó con un espectrofotómetro, con filtro de absorbancia de $650 \mathrm{~nm}$, tomando $0.50 \mathrm{DO}$ (densidad óptica) como punto de corte de acuerdo a lo especificado por el fabricante.

\section{Obtención de leucocitos}

Las muestras sanguíneas con anticoagulante, se centrifugaron a $1000 \times \mathrm{g}$ por $15 \mathrm{~min}$ para la separación de la capa flogística, la colección de leucocitos se realizó por aspiración con micropipeta y puntas estériles, posteriormente se conservaron a $-20{ }^{\circ} \mathrm{C}$ en tubos plásticos hasta su empleo.

PCR

La extracción de ADN de los leucocitos se realizó con el paquete comercial (UltraClean BloodSpin $^{\text {TM }}$ DNA Isolation kit, MO BIO Laboratories, Inc.) siguiendo las indicaciones del fabricante. Para la PCR sencilla se utilizaron los pares de iniciadores externos del gen Nc-5, Np 21 (5' GGG TGT GCG TCC AAT CCT GTA AC 3') y Np 4 (5' CCT CCC AAT GCG AAC GAA A 3'), que amplifican un fragmento de 380 pares de bases $(\mathrm{pb})$ (Yamage et al. 1996). La mezcla de reacción contenía $12.5 \mu \mathrm{L}$ de mezcla maestra (PCR Master Mix, Promega $\left.^{\mathrm{TM}}\right), 1 \mu \mathrm{L}$ de cada iniciador $(10 \mu \mathrm{M}), 2.5$ $\mu \mathrm{L}$ de agua libre de nucleasas y $8 \mu \mathrm{L}$ de ADN blanco para un volumen final de $25 \mu \mathrm{L}$. Las condiciones de ciclado fueron: $5 \mathrm{~min}$ a $95{ }^{\circ} \mathrm{C}, 1 \mathrm{~min}$ a $94^{\circ} \mathrm{C}, 1 \mathrm{~min}$ a $57{ }^{\circ} \mathrm{C}, 1 \mathrm{~min}$ a $72{ }^{\circ} \mathrm{C}$ ( 35 ciclos), y $7 \mathrm{~min}$ a $72{ }^{\circ} \mathrm{C}$. Para la PCR anidada, los iniciadores internos fueron Np 9 (5' GTT GCT CTG CTG ACG TGT CGT TG 3') y Np 10 (5' CTC AAC ACA GAA CAC TGA ACT (TC G 3'), que amplifican un fragmento de $224 \mathrm{pb}$. (Mc Innes et al. 2006). La mezcla de reacción contenía $12.5 \mu \mathrm{L}$ de mezcla maestra (PCR Master Mix, Promega $\left.{ }^{\mathrm{TM}}\right), 1 \mu \mathrm{L}$ de cada iniciador $(10 \mu \mathrm{M}), 5.5$ $\mu \mathrm{L}$ de agua libre de nucleasas y $5 \mu \mathrm{L}$ del producto de la PCR sencilla para un volumen final de $25 \mu \mathrm{L}$, empleando el siguiente protocolo de ciclado: $5 \mathrm{~min}$ a $94{ }^{\circ} \mathrm{C}$; $30 \mathrm{~s}$ a $94{ }^{\circ} \mathrm{C}, 20 \mathrm{~s}$ a $63{ }^{\circ} \mathrm{C}, 30 \mathrm{~s}$ a $72{ }^{\circ} \mathrm{C}$ (35 ciclos) y $10 \mathrm{~min}$ a $72{ }^{\circ} \mathrm{C}$ (Yao et al. 2009). Los productos de la amplificación se separaron en geles de agarosa al $2.5 \%$ teñidos con bromuro de etidio y visualizados bajo luz ultravioleta (UV), con un marcador de peso molecular de $100 \mathrm{pb}$ (Thermo Scientific ${ }^{T M}$, O'Gene Ruler 100 pb DNA Ladder). Para el control positivo, se utilizaron taquizoitos de $N$. caninum extraídos de placas comerciales de IFI $\left(\mathrm{VMRD}^{\mathrm{TM}}\right)$ y en el caso del control negativo, agua libre de nucleasas. En el periodo de estudio se registraron dos abortos, el primero de siete meses de gestación proveniente de una vaca de segundo parto y el segundo, de tres meses de gestación de una vaca con un parto, de éstos solo el último se pudo recuperar de forma adecuada, el cual se mantuvo en refrigeración hasta su traslado al laboratorio para luego congelarlo a $-20{ }^{\circ} \mathrm{C}$ hasta su utilización; de este feto se procesaron dos muestras de $50 \mathrm{mg}$ de diferentes zonas del cerebro que se sometieron a 
PCR con los iniciadores y protocolos antes descritos.

\section{Secuenciación}

Para la purificación de los productos de la PCR se recurrió al uso del paquete comercial (Min Elute Gel Extraction kit ${ }^{\mathrm{TM}}$ ) para su posterior alineación. Cuatro muestras de leucocitos y una de encéfalo positivas a la PCR sencilla se seleccionaron para su secuenciación automatizada y la posterior comparación con lo publicado en el Genbank por medio de la herramienta BLAST del NCBI, para corroborar la detección de $N$. caninum por la similitud de las secuencias.

\section{Análisis estadístico}

La concordancia entre las pruebas de ELISA y PCR al inicio del estudio, se calculó mediante la prueba Kappa (Felmer et al. 2006). Para el análisis de los datos, los animales se agruparon de acuerdo al estatus serológico, a la detección de ADN de $N$. caninum en leucocitos y organizados por mes de gestación o vacas sin preñez en su caso, así como las que parieron durante el estudio, además de estimar la prevalencia mensual y por trimestre de gestación.

\section{RESULTADOS Y DISCUSIÓN}

Se estimó una seroprevalencia del $85.3 \%$ a $N$. caninum en el hato al inicio del estudio por medio de ELISA. A nivel internacional las seroprevalencias reportadas para $N$. caninum son de $0.5 \%$ en Suecia (Bartels et al. 2006), $46.9 \%$ en Tailandia (Inpankaew et al. 2014) y de $49.2 \%$ en los Estados Unidos (Reichel et al. 2013), para sistemas de producción de leche intensivos, el único reporte en el SPLPE es de $28.8 \%$ en Uruguay (Furtado et al. 2011); mientras que en el ámbito nacional las prevalencias por serología oscilan entre $16 \%$ (SalinasMeléndez et al. 2005) y $72 \%$ (Morales et al. 2001). En tanto que, para el SPLPE, se reporta seroprevalencia de $51.7 \%$, lo que indica que más de la mitad de la población ha tenido contacto con $N$. caninum (Ojeda-Carrasco et al. 2016). Por otro lado, las absorbancias registradas con esta prueba para nueve vacas fue de entre 0.5 y 1 , de siete animales de 1.1 a 1.5 y de 13 individuos superiores a 1.51 , interpretando dichos valores como contacto reiterado con el agente, ya sea por reactivación de la enfermedad o reinfección.

Se amplificó ADN de $N$. caninum a partir de leucocitos de vacas infectadas de forma natural, empleando iniciadores internos y externos diseñados para uso en suero y tejido; los resultados de la PCR y el subsecuente análisis de las secuencias demostraron la detección del parásito $N$. caninum (Figura 1). Las prevalencias mensuales estimadas mediante PCR fueron de 55.8, 94.1, 100, 97.1 y $100 \%$ para los meses de marzo a julio, respectivamente, con promedio de $89.4 \%$. Con respecto a la edad de gestación (Tabla 1). Los resultados refuerzan la hipótesis de Okeoma et al. (2004) quienes sugieren que el fragmento de células blancas (leucocitos) alberga a los taquizoitos de $N$. caninum y utilizan a éstas para distribuirse entre los tejidos que afectan, ya que los anticuerpos circulantes pueden eliminar al parásito. En México, estudios realizados a partir de sangre han permitido la identificación de ADN de $N$. caninum en vacas lecheras del sistema de producción intensivo (Santana et al. 2010), de ganado productor de carne (Mondragón-Zavala et al. 2011) y para ganado productor de carne, leche y de doble propósito (Montiel-Peña et al. 2011), con prevalencias del 85,28 y $33.3 \%$, respectivamente. No se tienen reportes de la detección en el SPLPE, pero mediante PCR se reporta la detección de ADN en una muestra de cerebro de un feto abortado (Ojeda-Carrasco et al. 2016). Los iniciadores empleados (Yamage et al. 1999) no se emplean en México; aúnque se utilizan de forma amplia en otros países para la detección del parásito en muestras de tejido (Bergeron et al. 2001) y en suero (Mc Innes et al. 2006). Los pares de iniciadores pueden ser empleados para la amplificación de ADN a partir de leucocitos de vacas infectadas y de tejidos de fetos abortados; al respecto, se considera que la segunda reacción anidada de PCR aumenta la sensibilidad de la prueba (Yao et al. 2009); mientras que la PCR semianidada no lo hace cuando es empleado el gen Nc-5 (Baszler et al. 1999).

Por otra parte, algunos animales resultaron 


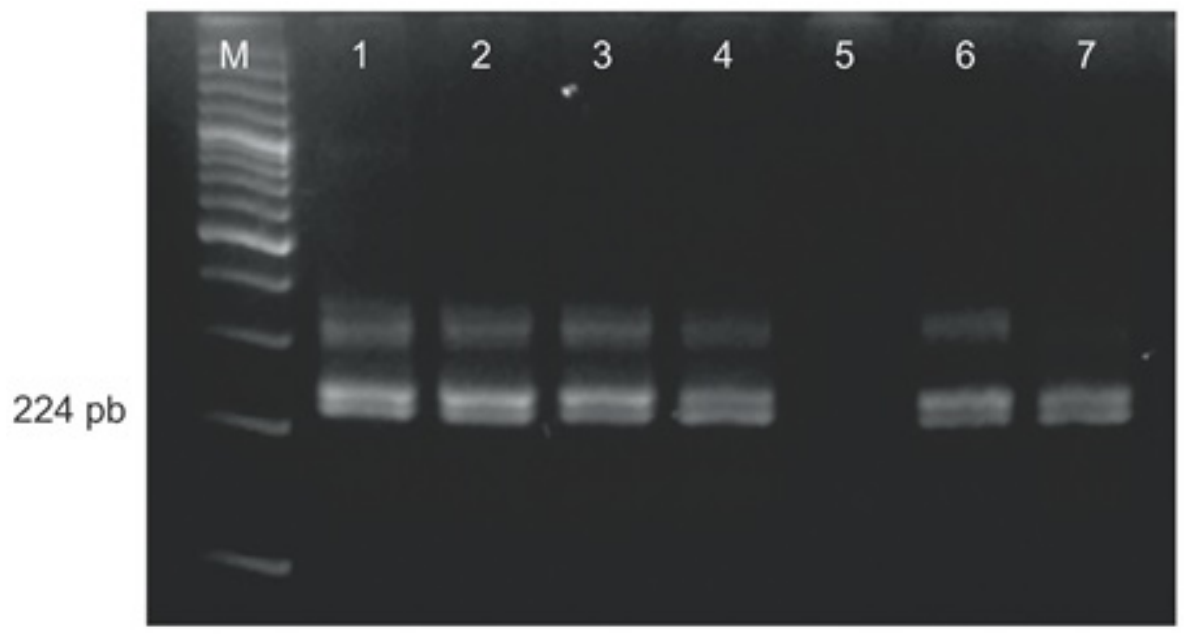

Figura 1. Productos amplificados por PCR anidado con iniciadores $\mathrm{Np} 9$ y $\mathrm{Np} 10$ de $N$. caninum. Carriles: M) marcador molecular de $100 \mathrm{pb} .1$ y 2) Control positivo (taquizoitos). $3)$ encéfalo de feto. 4) vaca 16.5 ) Control negativo. 6) vaca 17.7 ) vaca 26.

Tabla 1. Prevalencia de Neospora caninum por trimestre de gestación en leucocitos de vacas naturalmente infectadas del SPLPE mediante PCR anidada.

\begin{tabular}{cccccccccccc}
\hline Tercio de la gestación & \multicolumn{3}{c}{$1^{\circ}$} & \multicolumn{3}{c}{$2^{\circ}$} & \multicolumn{3}{c}{ 3er } \\
\hline Mes de gestación & 1 & 2 & 3 & 4 & 5 & 6 & 7 & 8 & 9 & vacía & parto \\
\hline PCR positivas & 13 & 16 & 15 & 13 & 14 & 13 & 11 & 10 & 6 & 41 & 9 \\
$\%$ & 86.7 & 84.2 & 93.7 & 86.7 & 87.5 & 92.8 & 100 & 90.1 & 66.6 & 93.2 & 100 \\
Total & 15 & 19 & 16 & 15 & 16 & 14 & 11 & 11 & 9 & 44 & 9 \\
\hline \% Trimestral & & 88.0 & & & 88.9 & & & 87.9 & 93.2 & 100
\end{tabular}

positivos a PCR pero negativos a ELISA y viceversa. Los resultados negativos en ELISA pueden estar relacionados con una infección primaria temprana en la cual el sistema inmunológico aún no genera una respuesta, o fue de baja intensidad; por otro lado, resultados negativos de la PCR tampoco excluyen la infección por $N$. caninum, debido a la reducida cantidad de protozoarios circulantes en la sangre del hospedero y la etapa de infección o reinfección (Yao et al. 2009).

En el muestreo inicial, de cinco vacas seronegativas una resultó positiva por medio de PCR; en contraparte, 11 vacas seropositivas resultaron negativas por PCR; posteriormente, una vaca permaneció negativa a la PCR por dos fechas consecutivas siendo positiva para la tres fechas siguientes. Otra fue positiva en el primer muestreo, negativa en el segundo y positiva las tres siguientes fechas; una fue negativa para la primera y cuarta fecha, pero positiva los tres fechas restantes; re- saltando que 18 de las 34 hembras bajo estudio resultaron positivas en los cinco muestreos a lo largo del estudio. En estudios previos en vacas de primera gestación del sistema intensivo, se reportó una prevalencia del 35, 75 y $50 \%$ por tercio de gestación (Santana et al. 2010), lo que difirere con lo encontrado en el presente estudio, que fue de un $88,88.9$ y $87.9 \%$, para el primer, segundo y tercer tercio de la gestación, respectivamente. El $100 \%$ de las vacas que parieron durante el periodo de estudio tuvieron la presencia del parásito, debido posiblemente a la inmunosupresión que presenta la vaca asociada al momento del parto. Mientras que el $93.2 \%$ de las vacas no preñadas fueron positivas por PCR anidado. Se detectó ADN del parásito de forma intermitente en algunos animales, como lo descrito por Santana et al. (2010), lo que implica que la parasitemia fluctúa a través del tiempo, posiblemente por acción inmunológica (Dubey et al. 2007). Al respecto Okeoma et al. (2005), detec- 
taron ADN de $N$. caninum a partir de la semana once de la gestación hasta antes del parto en vacas que abortaron y en las que no lo hicieron, lo que es similar a lo encontrado. Lo que sugiere que en el hato estudiado, se mantiene circulando $N$. caninum de forma continua, ya sea por transmisión vertical por mantenimiento de reemplazos persistentemente infectados, o bien de forma horizontal, por reinfección constante debida al consumo de forraje o agua contaminado. De las dos muestras de cerebro de fetos abortados, una fue positiva por PCR, mientras que el análisis de secuencia reflejó un $96 \%$ de similitud con la secuencia reportada por el Genbank (No. de acceso KF649848.1). Cuatro amplicones derivados del ADN de leucocitos se secuenciaron, los cuales tuvieron de un 91 a $96 \%$ de similitud con lo publicado (KF649848.1, AY665719.1). Se ha descrito que el SNC es el tejido más comúnmente infectado, recomendando tomar muestras de diferentes lugares, debido a que la distribución de los quistes dentro de este tejido no es uniforme (Dubey et al. 2007); la muestra positiva por PCR demuestra la infección congénita dentro del hato.

El índice Kappa $(K=0.41)$ indicó concordancia moderada entre la prueba de ELISA y PCR en el muestreo inicial; por lo que la presencia de anticuerpos no indica enfermedad o presencia del agente etiológico al momento del muestreo, ya que con la prueba ELISA se obtuvo una seroprevalencia de $85.3 \%$ y con PCR del $55.8 \%$ (Abbas et al. 2014). Contrario a lo realizado por Yao et al. (2009), en el presente estudio fue posible detectar una elevada presencia del parásito en sangre de vacas infectadas de forma natural. Lo que se puede atribuir a la muestra elegida en el estudio, ya que el uso de sangre completa coagulada reduce la probabilidad de que la muestra contenga un número considerable de células de la cuenta blanca, al igual que cuando se emplea sangre completa para la extracción de ADN (Santana et al. 2010, Mondragón-Zavala et al. 2011, Montiel-Peña et al. 2011). Por lo que el uso de células blancas para la búsqueda del agente en la presente investigación aumentó la posibilidad de detectar ADN del parásito (Okeoma et al. 2004). El uso de leucocitos de vacas infectadas incrementa la probabilidad de detectar ADN de $N$. caninum por PCR anidada con los iniciadores propuestos. Los oligos empleados en este estudio pueden ser utilizados para la detección de ADN de $N$. caninum en sangre y tejidos fetales con resultados aceptables.

\section{AGRADECIMIENTOS}

AI CONACYT por la beca para la realización de estudios de maestría y a la Secretaría de Educación Pública por el financiamiento del proyecto DSA $/ 103.5 / 14 / 7529$

\section{LITERATURA CITADA}

Abbas KA, Litchtman AH, Pillai S (2014) Cellular and molecular immunology. 8TH Edition, Elsevier Saunders, USA. 525p.

Adekunle BA and Ibikunle MA (2013) First report of antibodies to Neospora caninum in Nigerian cattle. The Journal of Infection in Developing Countries 7: 564-565.

Almería S (2013) Neospora caninum and wild life. Hindawi Publishing Corporation. ISRN Parasitology. Article ID 947347: 1-23.

Bartels CJ, Arnaiz-Seco J, Ruiz-Santa-Quitera A, Björkman C, Frössling J, Von Blumröder D, Conraths FJ, Schares G, Van Maanen C, Wouda W, Ortega-Mora LM (2006) Supranational comparison of Neospora caninum seroprevalences in cattle in Germany, The Netherland, Spain and Sweden. Veterinary Parasitology 137: 17-27.

Baszler TB, Lawrence JC, Maureen TL, and Bruce AM (1999) Detection by PCR of Neospora caninum in fetal tissues from spontaneous bovine abortions. Journal of the Clinical Microbiology 37: 4059-4064. 
Bergeron N, Girard C, Paré J, Fecteau G, Robinson J and Baillargeon P (2001) Rare detection of Neospora caninum in placentas from seropositive dams giving birth to full-term calves. Journal of Veterinary Diagnostic Investigation 13: 173-175.

Costa KS, Santos SL, Uzeda RS, Pinheiro AM, Almeida MAO, Araujo FR, McAllister MM and Gondim LF (2008) Chickens (Gallus domesticus) are natural intermediate host of Neospora caninum. International Journal for Parasitology 38: 157-159.

Donahoe SL, Lindsay SA, Krockenberger M, Phalen D, Slapeta J (2015) A review of neosporosis and pathologic findings of Neospora caninum infection in wild life. International Journal for Parasitology 4: 216-238.

Dubey JP, Schares G and Ortega-Mora LM (2007) Epidemiology and control of neosporosis and Neospora caninum. Journal of the Clinical Microbiology 20: 323-367.

Dubey JP, Jenkins MC, Ferreira LR, Choudhary S, Verma SK, Kwok OCH, et al. (2014) Isolation of viable Neospora caninum from brains of wild gray wolves (Canis lupus). Veterinary Parasitology 201: 150-153.

Espinoza-Ortega A, Espinosa-Ayala E, Bastida-López J, Castañeda-Martínez, Arriaga-Jordan CM (2007) Small-scale dairy farming in the highlands of central Mexico: Technical, economic and social aspects and their impact on poverty. Experimental Agriculture 43: 241-256.

Felmer R, Zúñiga J, Recabal M (2006) Estudio comparativo de un PCR anidado, ELISA y AGID en la detección del virus de la leucosis bovina en muestras de suero, sangre y leche. Archivos de Medicina Veterinaria 38: $137-141$

González-Warleta M, Castro-Hermida JA, Regidor-Cerrillo J, Benavides J, Álvarez-García G, Fuentes M, et al. (2014) Neospora caninum infection as a cause of reproductive failure in a sheep flock. Veterinary Research 45: 88-96

Hernández MP, Estrada FJG, Avilés NF, Yong AG, López GF, Solís MAD, et al. (2013) Tipificación de los sistemas campesinos de producción de leche del sur del estado de México. Universidad y Ciencia 29: 19-31.

INAFED (1998) Enciclopedia de los municipios y delegaciones de México. Estado de México. http://www.inafed.gob.mx/work/enciclopedia/EMM15mexico/municipios/15009a.html. Fecha de consulta 15 de junio de 2016.

Inpankaew T, Jittapalapong S, Mitchell TJ, Sununta C, Igarashi I, Xuan X (2014) Seroprevalence of Neospora caninum infection in dairy cows in Northern provinces, Thailand. Acta Parasitológica 59: 305-9.

Furtado A, Rosadilla D, Cattáneo M, Bermúdez J, Puentes R (2011) Occurrence of anti-Neospora caninum antibodies in small dairy farms in Uruguay. Ciencia Rural 41: 673-675.

López BJ, Arriaga JC, González DJG, Castelán OOA, Espinosa OA (2008) Variación económica a lo largo del año de los sistemas campesinos de producción de leche y su efecto en los índices de pobreza. Livestock research for rural development. 20 (32). http://www.lrrd.org/lrrd20/2/lope20032.htm. Fecha de consulta 20 de agosto del 2016.

Marques FCA, Headley AS, Figueredo-Pereira V, Taroda A, Barros D, Cunha IAL, et al. (2011) Neospora caninum: evaluation of vertical transmission in slaughtered beef cows (Bos indicus). Parasitolology Research 108: 1015-1019.

Mc Innes LR, Ryan LM, O'Handley RO, Sager H, Fershaw D, Palmer DG (2006) Diagnostic significance of Neospora caninum DNA detected by PCR in cattle serum. Veterinary Parasitology 142: 207-213. 
Mondragon-Zavala K, Cruz-Vázquez C, Medina-Esparza L, Ramos-Parra M, García-Vázquez Z (2011) Neospora caninum infection in beef cattle reared under grazing conditions in north-central México. Revista MVZ Córdoba 16: 2484-2490.

Montiel-Peña T, Romero-Salas D, García-Vázquez Z, Medina-Esparza L, Cruz-Vázquez C (2011) Neosporosis bovina en ranchos ganaderos de la zona norte del estado de Veracruz, México. Tropical and Subtropical Agroecosystems 13: 469-479.

Morales SE, Trigo FJ, Ibarra VF, Puente CE, Santacruz M (2001) Seroprevalence study of bovine neosporosis in México. Journal of Veterinary Diagnostic Investigation 13: 413-415.

Ojeda-Carrasco JJ, Espinosa-Ayala E, Hernández-García PA, Rojas-Martínez C, Álvarez-Martínez JA (2016) Seroprevalencia de enfermedades que afectan la reproducción de bovinos para leche con énfasis en neosporosis. Ecosistemas y Recursos Agropecuarios 3: 243-249.

Okeoma CM, Williamson NB, Pomroy WE, Stowell KM, Gillespie L (2004) The use of PCR to detect Neospora caninum DNA in the blood of naturally infected cows. Veterinary Parasitology 122: 307-315.

Okeoma CM, Stowell KM, Williamson NB, Pomroy WE (2005) Neospora caninum: quantification of DNA in the blood of naturally infected aborted and pregnant cows using real-time PCR. Experimental Parasitology 110: 48-55.

Salinas-Meléndez JA, Mora-García JJ, Zárate-Ramos JJ, Riojas-Valdés VM, Hernández-Vidal G, DávalosAranda G, Ramírez-Romero R, Galán-Alejo LC, Ávalos-Ramírez R (2005) Frecuencia de anticuerpos contra Neospora caninum en ganado bovino del noreste de México. Veterinaria México 36: 303-311.

Santana OI, Cruz-Vázquez C, Medina-Esparza L, Ramos PM, Castellanos MC, Quezada GD (2010) Neospora caninum: Detección de ADN en sangre durante la primera gestación de vaquillas infectadas naturalmente. Veterinaria México 41: 131-137.

Wilson DJ, Orsel K, Waddington J, Rajeev M, Sweeny AR, Joseph T, et al. (2016) Neospora caninum is the leading cause of bovine fetal loss in British Columbia, Canada. Veterinary Parasitology 218: 46-51

Yamage M, Flechtner O, Gottstein B (1996) Neospora caninum specific oligonucleotide primers for the detection of brain "cyst" DNA of experimentally infected nude mice by the polymerase chain reaction (PCR). Journal of Parasitology 825: 272-279.

Yao L, Yang N, Liu Q, Wang M, Zhang W, Qian WF, et al. (2009) Detection of Neospora caninum in aborted bovine fetuses and dam blood samples by nested PCR and ELISA and seroprevalence in Beijing and Tianjin, China. Parasitology 136: 1251-1256. 